\title{
Influence of the metal chips disintegration method on the physical and mechanical properties of metal powders obtained
}

\author{
Margarita Cherkasova ${ }^{1}$, Alexander Samukov ${ }^{2}$, Ivan Goncharov ${ }^{3}$, Anton Mezenin ${ }^{4}$ \\ ${ }_{1,2,4}$ REC Mekhanobr-Tekhnika, Saint Petersburg, Russia \\ ${ }^{3}$ Russian-Chinese Research Laboratory Functional Materials, Peter the Great St. Petersburg Polytechnic \\ University (SPbPU), Saint Petersburg, Russia \\ ${ }^{1}$ Corresponding author \\ E-mail: ${ }^{1}$ cherkasova_mv@mtspb.com, ${ }^{2}$ samykov_ad@mtspb.com, ${ }^{39670522 @ m a i l . r u, ~}$ \\ ${ }^{4}$ mezenin_ao@mtspb.com
}

Received 10 June 2020; accepted 18 June 2020

DOI https://doi.org/10.21595/vp.2020.21528

Check for updates

Copyright $(2020$ Margarita Cherkasova, et al. This is an open access article distributed under the Creative Commons Attribution License, which permits unrestricted use, distribution, and reproduction in any medium, provided the original work is properly cited.

\begin{abstract}
This paper presents the results obtained in comparative grinding studies of alloy metal chips using a ball mill and a vibrating mill. A comparison of the effective viscosity, bulk and tapped density in narrow size classes demonstrated higher rheological properties of the vibration grinding product and significant differences in the distribution of indicators by the size classes, depending on the grinding method. The specific yield and energy consumption indicators were established, which confirmed the superiority of vibration grinding over ball mill grinding. A visual assessment of the shape and surface condition of the ground particles is presented, conducted using a scanning electron microscope.
\end{abstract}

Keywords: additive manufacturing, metal powders, metal chips grinding, ball mill grinding of metals, vibrating mill grinding of metals, vibration effects, vibration fracturing mechanics.

\section{Introduction}

The applications of powder materials and their global usage are growing annually, which is further facilitated by the development of additive manufacturing in mechanical engineering. These advanced knowledge-intensive technologies require very high-quality dispersed powders. Their manufacturing method may directly affect the properties of the metal or alloy used. Powders with identical chemical compositions may have varying physical characteristics and may differ in processing properties, leading to significant variations in the conditions for the further transformation of the powders into finished products [1,2].

Mainly physical and mechanical methods and melt dispersion methods are currently used for the manufacture of metal powders $[3,4]$. At the same time, the waste generated in machining applications is an immense source of raw materials for manufacturing metal powders. This waste is usually generated in the manufacture of critical parts and contains valuable alloying components $[5,6]$. For such raw materials, mechanical treatment will be the best method of obtaining powders, ensures the transformation of the initial material into powder without any significant changes in its chemical composition. This will reduce the cost of the powders generated and eliminate the energy-intensive and non-environmentally friendly pyrometallurgical process of waste remelting, which has been used traditionally.

Ball mills are the most affordable and common industrial equipment for producing metal powders by mechanical grinding [7]. Grinding is ensured by impacts, abrasion and crushing: with the drum rotation, the grinding balls are raised by friction to a certain height and then fracture the material by freely falling and rolling.

However, in fine grinding, with finer particle sizes, the relative particle strength increases due to the reduction in the number of pre-fractured areas. The microcracks emerging in the first loading cycles may close under the influence of molecular forces. This "self-healing" effect of the particles 
may be reduced by increasing the load application rate and the frequency of exposure to force pulses, thus improving the fracture intensity due to the fatigue phenomena. In the case of a traditional ball mill, the impact intensity of the grinding medium is structurally limited by the so-called "critical" rotation speed, at which the centrifugal forces start pressing the grinding medium to the drum. These restrictions limit the specific performance of ball mills, which leads to a significant increase in energy consumption in the case of metal and alloy grinding and supports the feasibility of using more energy-efficient and energy-intensive devices.

Vibrating mills are a promising alternative, using similar main exposure mechanisms (impact, abrasion and cracking) to those in ball mills, but with the grinding media accelerations many times higher than the acceleration of gravity fundamentally limiting the traditional ball mills.

The previous studies of vibration crushing and grinding of metal chips [8] demonstrate the advantages of this type of equipment for obtaining metal powders. However, a better understanding of the physical fracturing processes in vibration grinding and their differences from the fracturing processes in traditional ball mill grinding required further research into the structure and properties of particles by various size fractions, following their comparative disintegration in these devices.

\section{Methodology}

The material for the comparative studies was represented by alloy metal machining chips with the nickel content of $77 \%$, without the metal-working oil. Before the grinding, the chips were crushed in a hammer mill to the particle size of less than $2.5 \mathrm{~mm}$.

For the vibration grinding, an eight-chamber continuous-discharge vibration roller mill was used, with the total chamber working volume of 8.3 liters. The vibrating mill housing was mounted on rubber shock absorbers; the vibrations were induced via an electrically driven unbalanced vibrator; the oscillation frequency was $19.5 \mathrm{~Hz}$; and the oscillation amplitude was $6.7 \mathrm{~mm}$. Rollers were used as the grinding media.

Grinding to the particle size of $51.5 \%$ less than $125 \mu \mathrm{m}$ was carried out in four stages. After each grinding stage the finished product with the particle size of less than $125 \mu \mathrm{m}$ was separated from the material discharged; the product of over $125 \mu \mathrm{m}$ was used as the feed for the subsequent grinding stage.

The traditional chip milling tests were carried out in an MSL-14K batch-operated cantilever-type laboratory ball mill with the drum working volume of 14 liters. The ball charge was $40 \%$; the ball diameter was 40,25 , and $20 \mathrm{~mm}$, with the percentage ratio of 50:34:16, respectively. The mill rotation rate was $71 \mathrm{rpm}$ ( $76 \%$ of the critical value). The grinding to the particle size of $63.1 \%$ less than 125 microns was completed in 87.5 hours.

The grain-size analysis for the fine classes was carried out using a AS-200U (ROTAP) impact testing sieve and Microsizer 201C laser particle analyzer. The research results were used to establish the grain-size characteristics of the grinding products, as shown in Fig. 1.

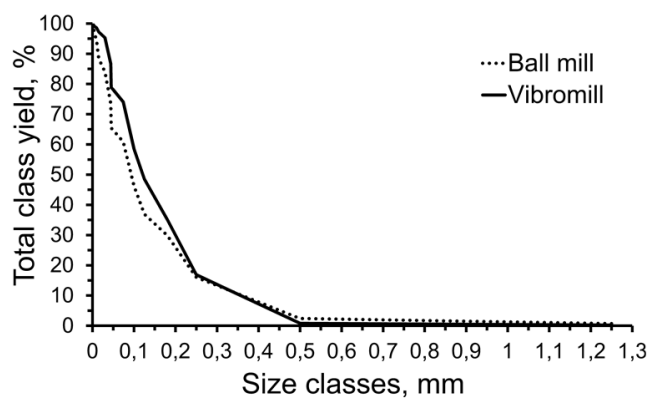

Fig. 1. Grain-size characteristics of ball and vibration grinding products

An analysis of the grain-size distribution for the grinding products indicates a certain degree 
of overgrinding in the ball mill with the difference of $11.6 \%$ in the content of the $<125 \mu \mathrm{m}$ class and $13.3 \%$ for the classes of $<74$ and $<44 \mu \mathrm{m}$. At the same time, for the coarse classes (over $250 \mu \mathrm{m}$ ), the particle content remains almost the same, with $16 \%$ and $16.9 \%$ for the ball and vibrating mills, respectively. These differences in the particle size distribution of grinding products are due to the differences in the grinding conditions. In the vibrating mill, the finished size class $(<125 \mu \mathrm{m})$ was separated from the mill discharge, while the class of over $125 \mu \mathrm{m}$ was returned to the mill for regrinding. In the ball mill, all the material was ground for 87.5 hours, without any intermediate removal of the finished size class, which contributed to the overgrinding.

Since the grinding machines compared operate in fundamentally different regimes (discrete and continuous grinding with coarse class regrinding), for a correct comparison, their performance and energy consumption indicators were calculated as specific values related to the working volume of the grinding chambers of the mills (Table 1).

Table 1. Specific yield and energy consumption indicators for the ball and vibrating mills

\begin{tabular}{|c|c|c|}
\hline Parameters & Ball mill & Vibrating mill \\
\hline Specific mill capacity, $\mathrm{kg} / \mathrm{m}^{3} \cdot \mathrm{h}$ & 5.0 & 97.1 \\
\hline Specific yield in the class of less than $125 \mu \mathrm{m}, \mathrm{kg} / \mathrm{m}^{3} \cdot \mathrm{h}$ & 2.9 & 50.1 \\
\hline Specific yield in the class of less than $74 \mu \mathrm{m}, \mathrm{kg} / \mathrm{m}^{3} \cdot \mathrm{h}$ & 1.9 & 23.2 \\
\hline Specific energy consumption for grinding, $\mathrm{kW} \cdot \mathrm{h} / \mathrm{kg}$ & 4.16 & 2.54 \\
\hline
\end{tabular}

According to Table 1, the ball mill is significantly inferior to the vibromill in terms of specific performance indicators as related to the working volume. For the feed material, the specific yield of the vibrating mill is 19.4 times higher than that of the ball mill and is 17.5 and 12.5 times higher in the classes of 125 and $74 \mu \mathrm{m}$, respectively. Moreover, the coarser the size class, the more intensive its fracturing becomes in a vibromill, as compared to a ball mill. The energy consumption for the vibrating mill grinding of metal chips to the particle size of $51.5 \%<125 \mu \mathrm{m}$ was $2.54 \mathrm{~kW} \cdot \mathrm{h} / \mathrm{kg}$, which is 1.64 times lower than the energy consumption for the ball mill grinding to the particle size of $63.1 \%<125 \mu \mathrm{m}(4.16 \mathrm{~kW} \cdot \mathrm{h} / \mathrm{kg})$. However, since a finer product is obtained in the ball mill with the same grinding size, the actual difference in energy consumption will be slightly lower.

For the narrow size classes of the grinding products the values of effective viscosity, bulk density and tapped density were determined. The effective viscosity was measured using a Hall device according to the method set out in ISO 4490-78, but using a non-standard funnel opening with the diameter of $10 \mathrm{~mm}$. Bulk and tapped density values were established using the methods in ISO 3923-2: 1981 and ISO 3953:2011, respectively.

The measurement results are presented in Table 2 and in Fig. 2 and 3.

Table 2. Specific yield and energy consumption indicators for the ball and vibrating mills

\begin{tabular}{|c|c|c|c|c|c|c|}
\hline \multirow{2}{*}{$\begin{array}{l}\text { Grain-size } \\
\text { class, mm }\end{array}$} & \multicolumn{2}{|c|}{ Effective viscosity, $\mathrm{E}^{0}$} & \multicolumn{2}{|c|}{ Bulk density, $\mathrm{g} / \mathrm{cm}^{3}$} & \multicolumn{2}{|c|}{ Tapped density, $\mathrm{g} / \mathrm{cm}^{3}$} \\
\hline & $\begin{array}{l}\text { Ball mill } \\
\text { grinding }\end{array}$ & $\begin{array}{l}\text { Vibrating mill } \\
\text { grinding }\end{array}$ & $\begin{array}{l}\text { Ball mill } \\
\text { grinding }\end{array}$ & $\begin{array}{l}\text { Vibrating mill } \\
\text { grinding }\end{array}$ & $\begin{array}{l}\text { Ball mill } \\
\text { grinding }\end{array}$ & $\begin{array}{l}\text { Vibrating mill } \\
\text { grinding }\end{array}$ \\
\hline$-1.25+0.500$ & No fluidity & 5.0 & 2.3 & 2.6 & 2.5 & 2.8 \\
\hline$-0.500+0.315$ & No fluidity & 4.4 & 2.3 & 3.2 & 2.4 & 3.4 \\
\hline$-0.315+0.250$ & 4.6 & 4.0 & 2.2 & 3.4 & 2.4 & 3.7 \\
\hline$-0.250+0.180$ & 4.4 & 4.0 & 2.2 & 3.3 & 2.4 & 3.4 \\
\hline$-0.180+0.125$ & 3.6 & 3.9 & 2.1 & 3.1 & 2.4 & 3.4 \\
\hline$-0.125+0.100$ & 4.0 & 3.8 & 2.2 & 2.6 & 2.4 & 3.0 \\
\hline$-0.100+0.074$ & 5.2 & 3.6 & 2.4 & 2.4 & 2.9 & 2.9 \\
\hline$-0.074+0.044$ & No fluidity & 5.4 & 2.4 & 2.3 & 2.7 & 2.8 \\
\hline-0.044 & No fluidity & No fluidity & 1.2 & 2.1 & 1.3 & 2.4 \\
\hline
\end{tabular}

The results obtained (Table 2, Fig. 2) indicate that the vibrating mill product demonstrates fluidity in a wider range of size classes $(-1250+44 \mu \mathrm{m})$ as compared with the ball mill product 
$(-315+74 \mu \mathrm{m})$. The weighted average effective viscosity values in the comparable size range of $(-315+74 \mu \mathrm{m})$ are also lower (3.9 versus 4.4$)$, which generally indicates higher rheological properties of the vibration grinding product.

The differences in the properties of the grinding products are also manifested in their other characteristics. As may be seen from Table 2 and Fig. 3, the vibration grinding product has higher bulk densities (tapped densities) in the range of $2.6(2.8)$ to $3.4(3.7) \mathrm{g} / \mathrm{cm}^{3}$ at finer particle sizes $(1250$ to $250 \mu \mathrm{m})$; and a further decrease in the particle sizes to less than $44 \mu \mathrm{m}$ smoothly reduces these values to $2.1(2.4) \mathrm{g} / \mathrm{cm}^{3}$. By contrast, the ball mill product demonstrates an almost imperceptible drop in its bulk density (tapped density) from $2.3(2.5)$ to $2.1(2.4) \mathrm{g} / \mathrm{cm}^{3}$ with a decrease in its particle size from 1250 to $125 \mu \mathrm{m}$, a smooth increase to $2.4(2.7) \mathrm{g} / \mathrm{cm}^{3}$ upon reaching the particle size of $44 \mu \mathrm{m}$ and a sharp drop to $1.2(1.3) \mathrm{g} / \mathrm{cm}^{3}$ with the further decrease in the particle size. The vibration grinding product has 1.41 times higher weighted average bulk density (tapped density) values than the Ball mill product, with 2.78 (3.09) versus 1.97 (2.19) $\mathrm{g} / \mathrm{cm}^{3}$, respectively. The visible differences in the distribution of bulk and tapped densities in the products compared not only indicate significant differences in the shapes of the ground particles, but also describe the differences in the fracturing processes.

For a visual assessment of the shape and surface condition of the ground particles, a TESCAN Mira 3 LMU scanning electron microscope with the 106x magnification and the accelerating voltage of 200 to $30000 \mathrm{~V}$ was used to obtain enlarged particle images (Table 3).

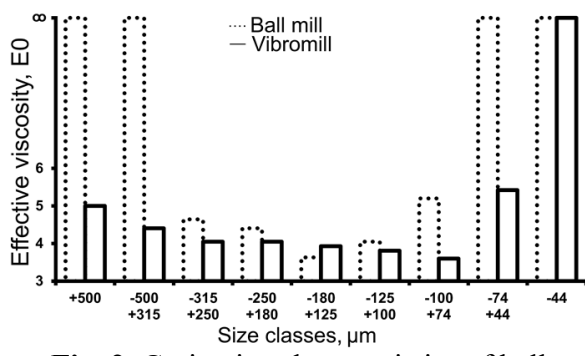

Fig. 2. Grain-size characteristics of ball and vibration grinding products

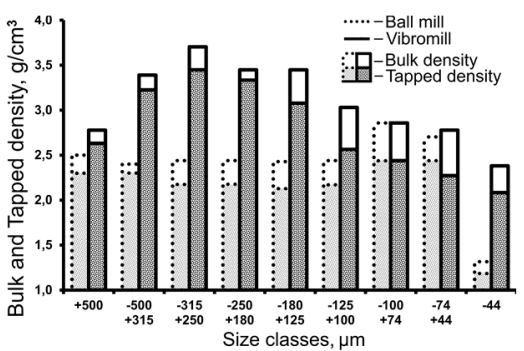

Fig. 3. Bulk and tapped density distribution diagram for narrow particle-size classes in ball and vibrating mill products

A study of the microimages obtained confirms the assumption that the difference in particle shapes causes the discrepancy in the bulk and tapped density values. Table 3 clearly indicates that the ball mill product is represented by plate-shaped and flaky particles in the entire range of particle sizes. It is also noticeable that, due to overgrinding, the class of less than $44 \mu \mathrm{m}$ contains a significant number of particles with the particle size below $5(10) \mu \mathrm{m}$, which explains the sharp bulk density drop in this class by the emergence of adhesion forces.

The vibration grinding product particles in the particle size classes of 1250 to $250 \mu \mathrm{m}$ are predominantly close in shape to a ball or a cube; with the further decrease in particle size, plate-shaped and flaky particles gradually emerge and multiply and represent the majority in the class of less than $44 \mu \mathrm{m}$.

The above differences in the physical and mechanical properties of ground particles may be explained by the nature of the mechanical interaction of the grinding media with the material ground in the devices compared. Based on the microimages obtained, it may be assumed that ball mill grinding with low-energy ball impacts on the particles of metal chips mainly causes surface deformations of the metal, which leads to slow particle splitting into plate-type (flaky) shapes with further cracking-off of finer particles. On the other hand, high-energy impacts of the grinding media in vibrating mills (caused by high accelerations) allow creating deep deformations in coarser metal particles, inducing volumetric cracks and subsequent fracturing with the formation of prevailing cuboid and spherical particles; and the fine size classes formed (less than $74 \mu \mathrm{m}$ ) are prone to splitting with the formation of flakes and plates. 
INFLUENCE OF THE METAL CHIPS DISINTEGRATION METHOD ON THE PHYSICAL AND MECHANICAL PROPERTIES OF METAL POWDERS OBTAINED. Margarita CHERKasova, AleXANDER SAmukov, IVAN GONCHAROV, ANTON MEZENIN

Table 3. Micro images of ground particles by narrow particle-size classes

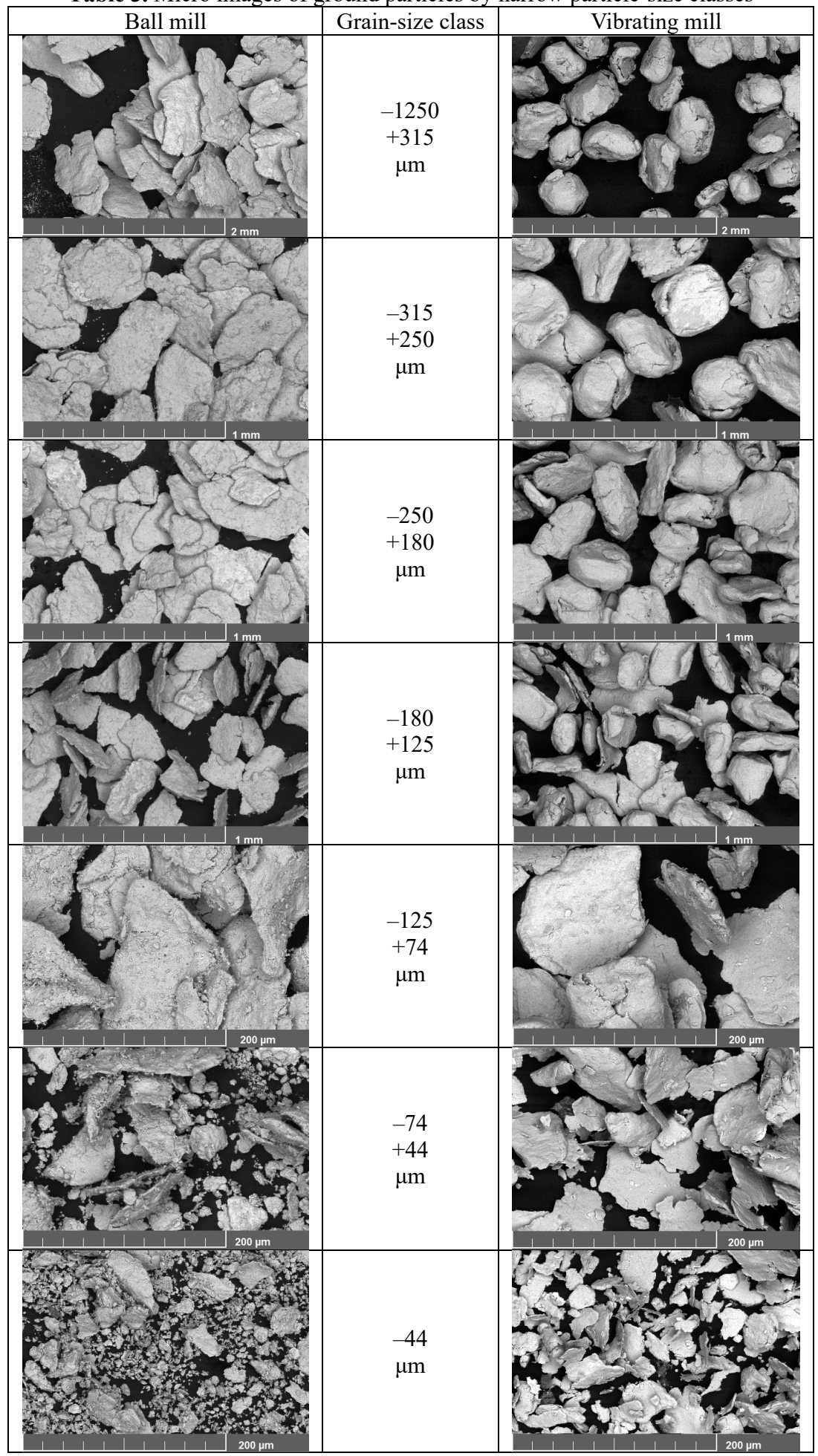




\section{Conclusions}

1) The specific feed capacity of a vibrating mill exceeds that of a ball mill by a factor of 19.4 and is 17.5 and 12.5 times higher in the classes of less than 125 and $74 \mu \mathrm{m}$, respectively. Moreover, the coarser the size class, the more intensive its fracturing becomes in a vibrating mill, as compared to a ball mill.

2) The energy consumption for metal chip grinding in a vibrating mill is 1.64 times lower than in a ball mill; however, since a finer product is obtained in ball mills with the same grinding size, the difference in energy consumption will be slightly lower.

3 ) The vibrating mill product has fluidity in a wider range of particle sizes, as compared to the ball mill product, which generally indicates higher rheological properties of the vibration grinding product.

4) The values of bulk density (tapped density) differ significantly depending on the grinding method in terms of the nature of their distribution by the size classes. The vibration grinding product has 1.41 higher weighted average density values.

5) The ball mill product is represented by plate-shaped and flaky particles in the entire range of particle sizes. By contrast, particles of the vibration grinding product are predominantly close in shape to a ball or a cube in the particle size classes of 1250 to $250 \mu \mathrm{m}$; with the further decrease in particle size, however, the number plate-shaped and flaky particles increases.

\section{Acknowledgements}

We are very grateful to OOO VA Insalt for providing the Microsizer 201C analyzer, as well as to the research team of Peter the Great St. Petersburg Polytechnic University.

The study was carried out under the grant issued by the Russian Science Foundation (Project No. 17-79-30056).

\section{References}

[1] Frazier W. E. Metal additive manufacturing: a review. Journal of Materials Engineering and Performance, Vol. 23, Issue 6, 2014, p. 1917-1928.

[2] Xueyang C., Lei Y., Wei Li, Zhiyuan W., Frank L. Newkirk J. Effect of powder particle size on the fabrication of Ti-6Al-4V using direct laser metal deposition from elemental powder mixture. Journal of Mechanics Engineering and Automation, Vol. 6, 2016, p. 348-355.

[3] Francisco Paula Gómez Cuevas Metals powders: synthesis and processing. Metals, Vol. 9, Issue 12, 2019, p. 1358.

[4] Popovich A., Sufiiarov V. Metal powder additive manufacturing. IntechOpen, 2016, https://doi.org/10.5772/63337.

[5] Thornton A., Saad J., Clayton J. Measuring the critical attributes of AM powders. Metal Powder Report, Vol. 74, Issue 6, 2019, p. 314-319.

[6] Fullenwider B., Kiani P., Schoenung J. M., Ma K. From Recycled Machining Waste to Useful Powders for Metal Additive Manufacturing. Springer Briefs in Applied Sciences and Technology, 2019.

[7] Vaisberg L., Safronov A. Vibratory disintegration application in processing of different materials. Obogashchenie Rud (Mineral Processing Journal), 2018, https://doi.org/10.17580/or.2018.01.01.

[8] Cherkasova M., Samukov A., Dmitriev S. Vibration technologies for producing metal powders. Vibroengineering Procedia, Vol. 25, 2019, p. 208-213. 